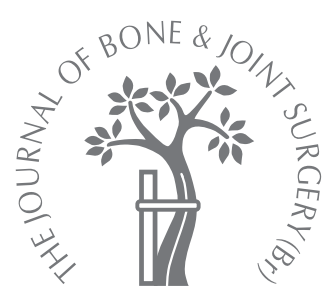

M. Takeda,

H. Higuchi,

M. Kimura,

Y. Kobayashi,

M. Terauchi,

K. Takagishi

From Gunma

University Graduate

School of Medicine,

Gunma, Japan

\title{
Spontaneous osteonecrosis of the knee
}

\author{
HISTOPATHOLOGICAL DIFFERENCES BETWEEN EARLY AND \\ PROGRESSIVE CASES
}

M. Takeda, MD, Research

Fellow

- H. Higuchi, MD, PhD,

Assistant Professor

K. Takagishi, MD, PhD,

Professor and Chairman

Department of Orthopaedic

Surgery

Gunma University Graduate

School of Medicine, 3-39-22

Showa, Maebashi, Gunma 371

8511, Japan.

M. Kimura, MD, PhD,

Director

I. Kobayashi, MD, PhD,

Associate Director

Gunma Sports Medicine

Research Centre

Zenshukai Hospital, 1381

Ninomiya, Maebashi, Gunma

379-2117, Japan.

M. Terauchi, MD, PhD,

Consultant Orthopaedic

Surgeon

Gunma Chuo General Hospital,

1-7-13 Kounmachi, Maebashi,

Gunma 371-0025, Japan.

Correspondence should be sent to Dr M. Takeda; e-mail:

take32@siren.ocn.ne.jp

(C)2008 British Editorial Society of Bone and Joint Surgery doi:10.1302/0301-620X.90B3. $18629 \$ 2.00$

$J$ Bone Joint Surg $[\mathrm{Br}]$

2008;90-B:324-9.
Received 11 September 2006;

Accepted after revision 16

October 2007

\begin{abstract}
We prospectively examined the physical and imaging findings, including MRI, of 23 patients with spontaneous osteonecrosis of the knee after obtaining informed consent to acquire tissue specimens at surgery. There were four men and 19 women, with a mean age of 67.5 years (58 to 77). Plain radiographs were designated as stages 1, 2, 3 or 4 according to the classification of Koshino. Five knees were classified as stage 1, five as stage 2, seven as stage 3 and six as stage 4 . The histological specimens were stained with haematoxylin and eosin and tetrachrome.
\end{abstract}

In the early stages of the condition, a subchondral fracture was noted in the absence of any features of osteonecrosis, whereas in advanced stages, osteonecrotic lesions were confined to the area distal to the site of the fracture which showed impaired healing. In such cases, formation of cartilage and fibrous tissue, occurred indicating delayed or nonunion. These findings strongly suggest that the histopathology at each stage of spontaneous osteonecrosis is characterised by different types of repair reaction for subchondral fractures.

A painful lesion which was localised to the medial femoral condyle in the elderly was defined by Ahlbäck, Bauer and Bohne ${ }^{1}$ in 1968 as spontaneous osteonecrosis of the knee, a definition which was based upon its radiological and pathological features. Since then, various studies have discussed the diagnosis and treatment of the condition..$^{2-8}$ In particular, recent advances in MRI have contributed greatly to the establishment of the diagnosis; its sensitivity has been reported to be higher than that of conventional plain radiography or bone scintigraphy. ${ }^{9}$ Moreover, early changes which are difficult to diagnose by plain radiography have become detectable by MRI. ${ }^{9-11}$ The radiological classification system described by Koshino $^{3}$ is usually used to describe these lesions. In stage 1 no abnormalities are seen. In stage 2 , a radiolucent oval shadow appears in the subchondral area of the weight-bearing portion of the femoral condyle. This area expands and is surrounded by a sclerotic halo in stage 2 . The subchondral bone plate distal to the radiolucency collapses and is visible as a calcified plate. In stage-4 lesions, osteophytes and osteosclerosis are seen in both the ipsilateral tibial condyle and the involved femoral condyle.

The MRI criteria used for the diagnosis of spontaneous osteonecrosis have been described previously. ${ }^{12,13}$ Normal intensity on T1-weighted images from fat in the marrow is replaced by a discrete area of low-signal intensity in the affected medial femoral condyle, with a focal area of lower signal intensity in the periphery of the discrete area. T2-weighted images typically show high-signal intensity in the corresponding area, with an associated focal area of low-signal intensity in the central lesion (bone-marrow oedema pattern).

Different views on the pathogenesis of the condition have been proposed, which mainly suggest that any increase in intraosseous pressure because of a local inflammatory response and/or impaired microcirculation within the bone, can cause spontaneous osteonecrosis. ${ }^{14}$ Microfractures in the osteoporotic subchondral bone plate, which allow fluids to be expressed from overlying cartilage into the marrow can lead to increased local marrow pressure and give rise osteonecrosis. ${ }^{4}$ In addition, a recent report proposed that osteonecrosis results from a subchondral insufficiency fracture. ${ }^{12}$ The pathogenesis therefore remains controversial. Histological examination of early lesions is extremely important in establishing the pathogenesisis of this condition. However, a search of the literature did not reveal any pathological studies of early lesions except for a report of three patients with stage- 2 
Table I. Clinicopathological characteristics of the 23 patients with spontaneous osteonecrosis of the knee

\begin{tabular}{|c|c|c|c|c|c|c|c|c|c|}
\hline Case & Gender & $\begin{array}{l}\text { Age } \\
\text { (yrs) }\end{array}$ & Side & $\begin{array}{l}\text { Height } \\
\text { (cm) }\end{array}$ & $\begin{array}{l}\text { Weight } \\
\text { (kg) }\end{array}$ & $\begin{array}{l}\text { Duration of pre-operative } \\
\text { pain (days) }\end{array}$ & $\begin{array}{l}\text { Radiological } \\
\text { stage }^{3}\end{array}$ & $\begin{array}{l}\text { Method of obtaining } \\
\text { specimen }\end{array}$ & $\begin{array}{l}\text { Histological } \\
\text { group }^{12}\end{array}$ \\
\hline 1 & $\mathrm{~F}$ & 77 & $\mathrm{R}$ & 138 & 42 & 45 & 1 & Biopsy & I \\
\hline 2 & $\mathrm{~F}$ & 65 & $\mathrm{~L}$ & 144 & 57 & 68 & 1 & Biopsy & I \\
\hline 4 & $\mathrm{~F}$ & 67 & $L$ & 150 & 54 & 145 & 1 & Biopsy & I \\
\hline 5 & $\mathrm{~F}$ & 72 & $L$ & 146 & 58 & 70 & 1 & Biopsy & I \\
\hline 8 & $F$ & 76 & $L$ & 140 & 50 & 120 & 2 & Biopsy & I \\
\hline 9 & M & 58 & $L$ & 174 & 63 & 83 & 2 & Biopsy & I \\
\hline 10 & $F$ & 58 & $L$ & 154 & 70 & 190 & 2 & Biopsy & 1 \\
\hline 11 & $\mathrm{~F}$ & 68 & $L$ & 155 & 49 & 165 & 3 & Biopsy & II \\
\hline 12 & $\mathrm{~F}$ & 70 & $\mathrm{R}$ & 150 & 43 & 150 & 3 & Biopsy & II \\
\hline 13 & $\mathrm{~F}$ & 59 & $\mathrm{~L}$ & 148 & 73 & 94 & 3 & Biopsy & II \\
\hline 17 & $\mathrm{~F}$ & 75 & $\mathrm{~L}$ & 153 & 65 & 240 & 3 & UKR ${ }^{*}$ & II \\
\hline 18 & $\mathrm{~F}$ & 71 & $\mathrm{~L}$ & 151 & 54 & 360 & 4 & UKR & II \\
\hline 19 & $\mathrm{~F}$ & 69 & $\mathrm{R}$ & 148 & 56 & 202 & 4 & Biopsy & II \\
\hline 20 & $F$ & 75 & $\mathrm{R}$ & 150 & 43 & 342 & 4 & UKR & III \\
\hline 21 & M & 63 & $\mathrm{R}$ & 155 & 63 & 150 & 4 & Biopsy & III \\
\hline 22 & $F$ & 69 & $\mathrm{~L}$ & 146 & 70 & 180 & 4 & Biopsy & II \\
\hline 23 & $\mathrm{M}$ & 67 & $L$ & 177 & 88 & 150 & 4 & Biopsy & II \\
\hline
\end{tabular}

disease described by Yamamoto and Bullough. ${ }^{12}$ If a subchondral fracture is the main cause, as reported by these authors, it is still not known why different changes occur, as classified by plain radiography. We, therefore, decided to focus on painful stage- 1 and stage- 2 lesions as classified by MRI and plain radiography, in order to analyse their pathological features.

\section{Patients and Methods}

We performed a prospective study after obtaining informed consent to use tissue specimens. We examined 23 knees in 23 patients who had been diagnosed with spontaneous osteonecrosis of the knee by physical and imaging findings, and who had undergone surgery between July 2000 and December 2004. There were four men and 19 women, with a mean age of 67.5 years ( 58 to 77 ). No patient had a history of taking steroids or excess alcohol consumption. The clinical symptoms were evaluated based upon the criteria proposed by Ahlbäck et al. ${ }^{1}$ Only elderly patients with an acute onset and whose lesions were localised to the medial femoral condyle were analysed. Patients aged over approximately 60 years had characteristic symptoms such as acute pain localised to the region of medial femoral condyle accompanied by night pain without any apparent cause. The diagnosis was based upon MRI findings.

Five patients had stage- 1 lesions, five stage-2, seven stage- 3 and six stage-4 lesions (Table I).

The three-dimensional (3D) position of the lesion was determined by pre-operative MRI and fluoroscopy. In addition, at arthroscopy tissue was biopsied from at least two sites in the weight-bearing area which showed changes in the articular cartilage, using a bone-biopsy needle (Ostycut; Angiomed, Karlsruhe, Germany). Multiple drilling with Kirschner wires was then performed for decompression in 20 patients. In the remaining three, tissue was obtained at the time of unicompartmental knee replacement (UKR).

All the specimens were immediately fixed in $10 \%$ formalin solution. After decalcification in $5 \%$ nitric acid, they were processed and embedded in paraffin. Sections, $7 \mathrm{~mm}$ thick, were prepared and routinely stained with haematoxylin and eosin to determine the morphological features, and with tetrachrome staining to identify primary osteoid and the formation of newly mineralised bone. ${ }^{15}$ Osteonecrosis was microscopically diagnosed if it was confirmed that there was both bone necrosis, as evidenced by empty lacunae which did not contain stainable osteocytes, and fat necrosis, resulting from the breakdown of the walls of fat cells. ${ }^{16}$ Since all fractures lead to bone necrosis, necrotic regions which were only seen around the fracture line were not classified as osteonecrosis. ${ }^{17-19}$ We also divided lesions of spontaneous osteonecrosis into three histological groups according to the classification of Yamamoto and Bullough ${ }^{12}$ as follows: group I, a subchondral fracture with no evidence of osteonecrosis; group II, a subchondral fracture with associated focal osteonecrosis confined to the region between the fracture line and the articular surface; group III, indeterminate findings because the articular cartilage and underlying tissue had become detached from the femoral condyle.

\section{Results}

The mean time between the onset of pain and surgery was 102 days (45 to 180) for patients with stage- 1 disease, 143 


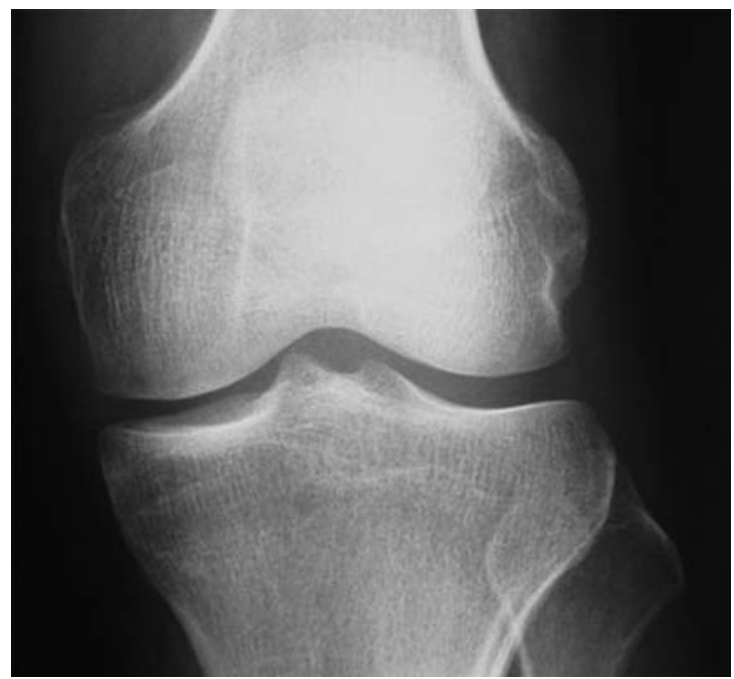

Fig. 1a

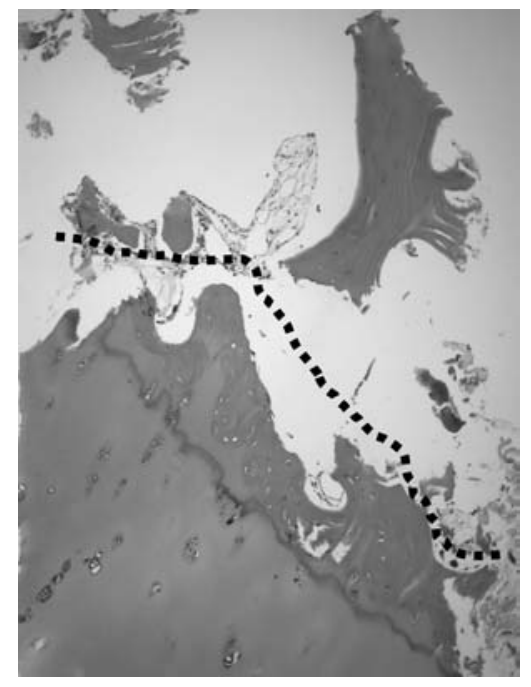

Fig. 1c

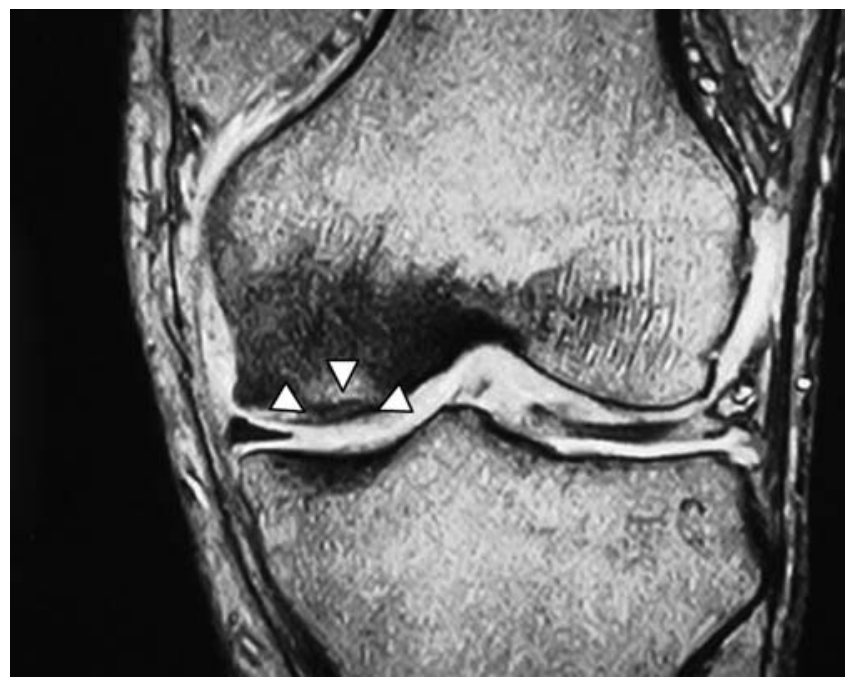

Fig. 1b

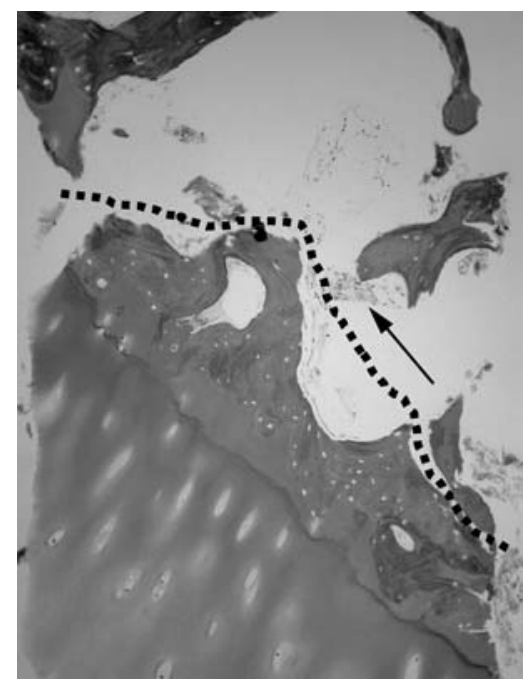

Fig. 1d

Figure 1a - Plain radiograph of case 2 showing no radiolucencies, indicating stage-1 disease Figure $1 \mathrm{~b}-\mathrm{T} 2$-weighted MR image showing a low-signal-intensity area in the subchondral portion of the weight-bearing area of the medial femoral condyle, which was surrounded by an oval area of highsignal intensity $(6.4 \mathrm{~mm}$ long $\times 10.6 \mathrm{~mm}$ wide; arrowheads). This was surrounded by a diffuse low-intensity area. Figures $1 \mathrm{c}$ and 1d - Photomicrographs demonstrating bone marrow at top, articular cartilage at bottom. Figure 1c-There is no osteonecrosis between the line of the fracture (broken line) and the articular cartilage (haematoxylin and eosin $\times 100$ ). Figure $1 d-$ There is fibrous tissue (arrow) around the line of the fracture (broken line), but formation of osteoid was not apparent, suggesting the early stages of repair (tetrachrome $\times 100$ ).

(83 to 190) for those with stage-2, 167 (83 to 240) for those with stage-3 and 231 (150 to 360) for those with stage-4 lesions (Table I). The histopathology in each stage of spontaneous osteonecrosis was characterised as follows. In stage 1, all five patients showed the features of group I, with no evidence of osteonecrosis. Fibrous tissue was present around the fracture line, but osteoid formation was not active, suggesting an early reparative reaction (Fig. 1). In stage 2 , all five patients also showed the features of group I, with no evidence of antecedent osteonecrosis. However, a reparative reaction was seen, mainly consisting of osteoid and the formation of immature bone (Fig. 2). In stage 3, all seven patients showed the features of group II, with an osteonecrotic lesion confined to the area distal to the fracture line. There was inadequate repair tissue on the articular-cartilage side of the fracture line which was interpreted as delayed union (Fig. 3). Four of the six patients in stage 4 showed the features of group II, with empty lacunae and necrotic debris confined to the area distal to the gap which was interpreted as showing nonunion (Fig. 4). The remaining two patients in stage 4 were classified as having a group-III lesion, in which it was not possible to detect either a fracture or necrosis (Table I).

\section{Discussion}

Our study is the first to investigate the histological features of a group of patients with stage- 1 and stage- 2 lesions, and shows that the common pathological features are subchondral fracture and repair reactions without osteonecrosis. This strongly suggests that the condition results from subchondral fracture and not from osteonecrosis because of ischaemia; this is consistent with the sudden onset of joint 


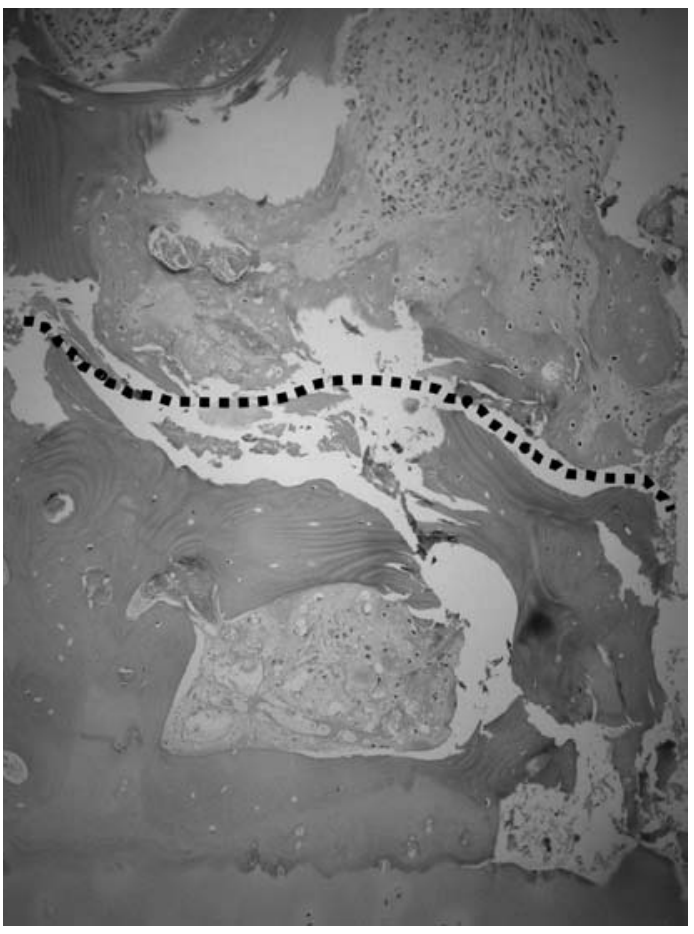

Fig. 2a

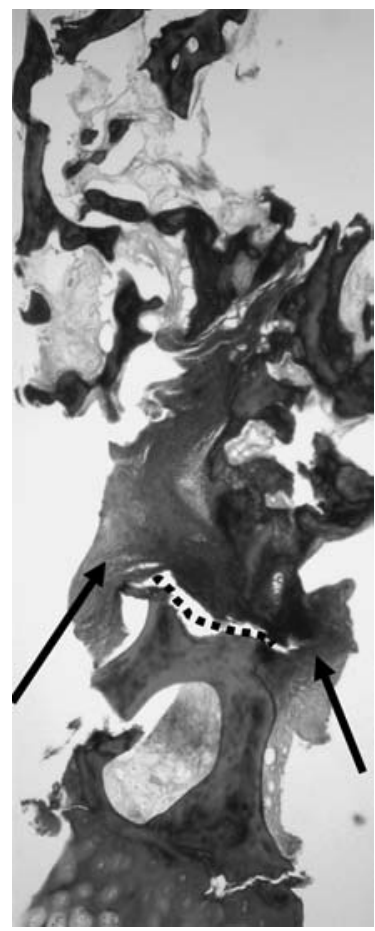

Fig. 2b
Photomicrographs demonstrating bone marrow at top, articular cartilage at bottom. Figure $2 \mathrm{a}-$ There is a fracture line (broken line) in the subchondral area but no osteonecrosis between the fracture line and the articular cartilage (haematoxylin and eosin $\times 100$ ). Figure $2 b-$ There is active formation of osteoid (arrows) cross-linking the fracture line (broken line) (tetrachrome $\times$ 100).

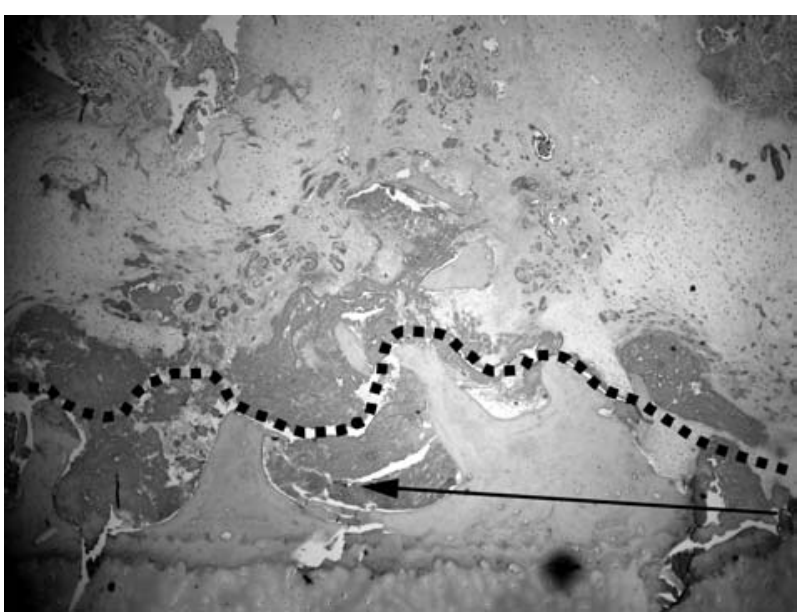

Fig. 3a

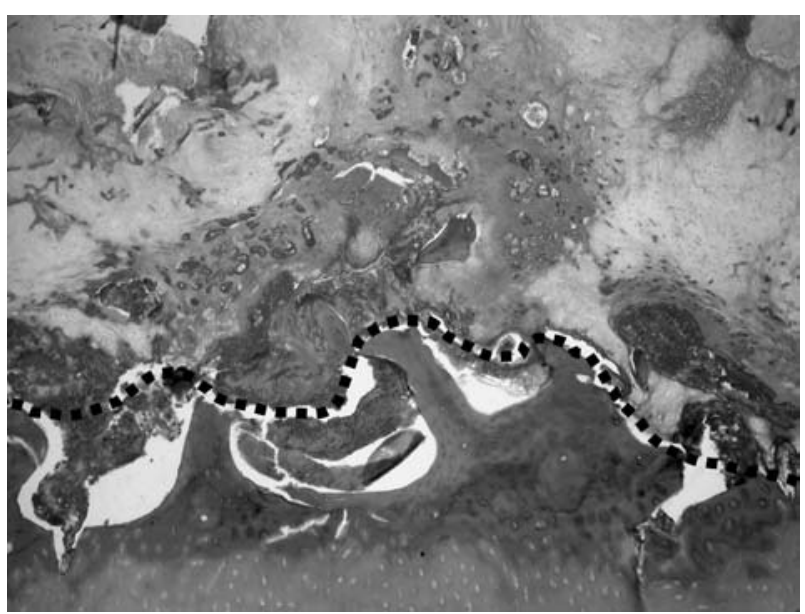

Fig. $3 b$

Photomicrographs demonstrating bone marrow at top, articular cartilage at bottom. Figure 3a - There are empty lacunae and necrotic debris (arrow) on the articular-cartilage side (broken line) (haematoxylin and eosin $\times 100$ ). Figure $3 b-$ There is granulation tissue rich in blood vessels on the bonemarrow side of the fracture line (broken line) with inadequate entry of reparative tissue on the articular-cartilage side. The features could be interpreted as showing delayed union (tetrachrome $\times 40$ ).

pain, a clinical hallmark. A similar view concerning avascular necrosis of the femoral head has been proposed, in which it has been demonstrated that it is the crushing of necrotic trabeculae in an osteonecrotic focus which causes the pain. ${ }^{20,21}$ Plain radiography of insufficiency fractures may not show an abnormality for two to three weeks or more after the onset of pain, ${ }^{22}$ consistent with a similar observa- tion in spontaneous osteonecrosis of the knee. ${ }^{22}$ In addition, Lotke et $\mathrm{al}^{4}$ reported that spontaneous resolution occurs in some patients with this condition. This is understandable, if the spontaneous osteonecrosis resulted from a subchondral insufficiency fracture.

When examining an osteonecrotic lesion histopathologically, small necrotic regions around the fracture line cannot 


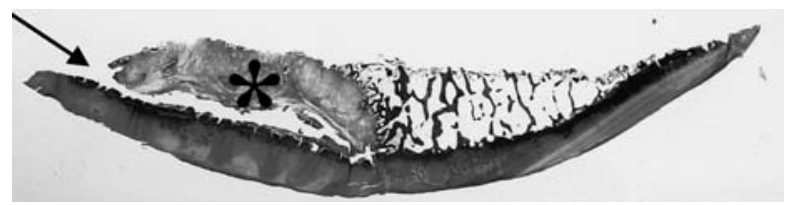

Fig. $4 a$

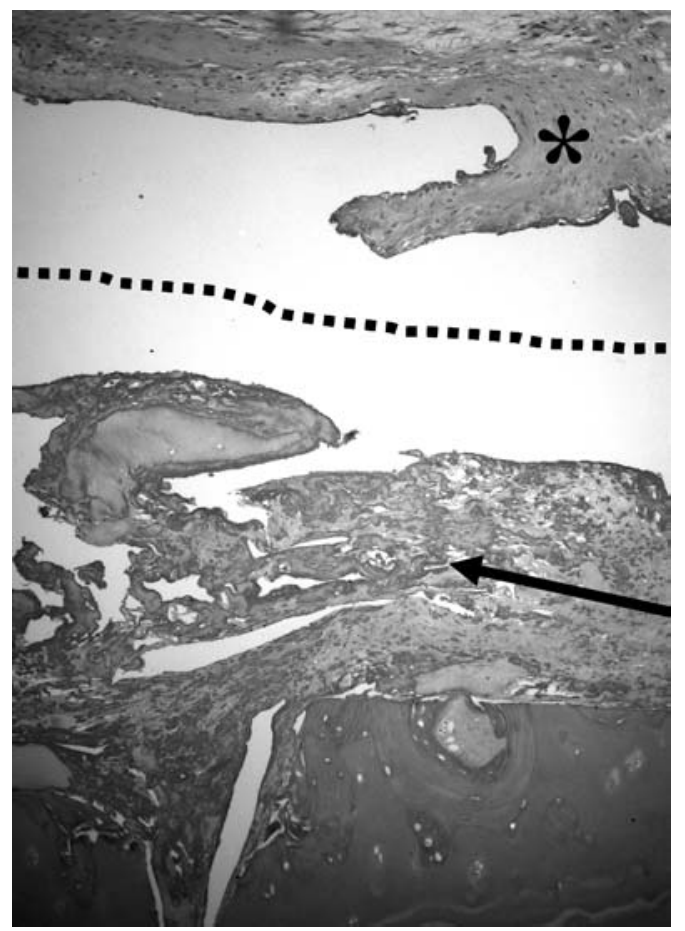

Fig. 4b

Photomicrographs demonstrating bone marrow at top, artcular cartilage at bottom. Figure $4 a$ - Photomicrograph showing a subchondral fracture line which was completely separated, forming a gap (arrow). Fibrous tissue (asterisk) is laid down parallel with the gap (tetrachrome $\times 10$ ). Figure $4 b$ - Photomicrograph showing empty lacunae and necrotic debris (arrow) on the articular-cartilage side of the gap (broken line). There was no continuity between the fibrous tissue (asterisk) on the bone-marrow side and necrotic tissue on the articular-cartilage side. The features could be interpreted as showing nonunion (haematoxylin and eosin $\times 100$ ).

be interpreted as indicating osteonecrosis. ${ }^{17-19}$ In the published histopathological reports, the lesion of spontaneous osteonecrosis involved only a small area of subchondral tissue, whereas in classical osteonecrosis associated with corticosteroid therapy, or for lesions found in the head of the femur, the affected area was larger and wedge-shaped. ${ }^{1,23}$ It may be that in earlier publications small necrotic regions around the fracture line were misdiagnosed as osteonecrosis. We also noted empty lacunae in trabeculae distal to the fracture line, and interpreted them as secondary changes associated with fracture.

If a subchondral fracture is the first event, the question remains as to the cause of the changes seen on plain radiographs and the interpretation of the advanced stages of the condition. The histological features of advanced lesions closely resemble those of delayed union or nonunion. ${ }^{17,24}$ These include a subchondral fracture which occurs first, followed by repair, although weight-bearing and other factors can impair healing. Repeated movement of the fragments accounts for hyperaemia, while gradually more of the bone ends undergo resorption as a crack becomes a cavity, or a linear fracture becomes a gap. It seems reasonable to assume that damage to ingrowing vascular tissue may result from incomplete immobilisation, with resulting formation of cartilage and fibrous tissue indicative of delayed or nonunion. ${ }^{24}$ Consequently, and while in a state of delayed or nonunion, an unstable fragment distal to the fracture may become detached, lose its blood supply, and result in osteonecrosis.

This suggests that if a subchondral fracture can be diagnosed early by using MRI before delayed or nonunion occurs, remission can be expected after conservative treatment.

In summary, in early lesions of spontaneous osteonecrosis, we noted a subchondral fracture alone in the absence of the features of osteonecrosis. In advanced stages, we observed osteonecrotic lesions which were confined to the area distal to the site of the fracture. Advanced stages represent impaired fracture healing with subsequent formation of cartilage and fibrous tissue, a feature of delayed or nonunion.

No benefits in any form have been received or will be received from a commercial party related directly or indirectly to the subject of this article.

\section{References}

1. Ahlbäck S, Bauer GC, Bohne WH. Spontaneous osteonecrosis of the knee. Arthritis Rheum 1968;11:705-33.

2. Aglietti P, Insall JN, Buzzi R, Deschamps G. Idiopathic osteonecrosis of the knee: aetiology, prognosis and treatment. J Bone Joint Surg [Br] 1983;65-B:588-97.

3. Koshino $\mathbf{T}$. The treatment of spontaneous osteonecrosis of the knee by high tibial osteotomy with and without bone-grafting or drilling of the lesion. J Bone Joint Surg [Am] 1982;64-A:47-58

4. Lotke PA, Ecker ML, Alavi A. Painful knees in older patients: radionuclide diagnosis of possible osteonecrosis with spontaneous resolution. J Bone Joint Surg [Am] 1977;59-A:617-21

5. Kantor H. Bone marrow pressure in osteonecrosis of the femoral condyle (Ahlbäck's disease). Arch Orthop Trauma Surg 1987;106:349-52.

6. Lotke PA, Abend JA, Ecker ML. The treatment of osteonecrosis of the medial femoral condyle. Clin Orthop 1982;171:109-16.

7. Muheim G, Bohne WH. Prognosis in spontaneous osteonecrosis of the knee: investigation by radionuclide scintimetry and radiography. J Bone Joint Surg [Br] 1970;52B:605-12.

8. Marulanda GA, Seyler TM, Sheikh N, Mont MA. Percutaneous drilling for the treatment of secondary osteonecrosis of the knee. J Bone Joint Surg [Br] 2006;88B:740-6.

9. Pollack MS, Dalinka MK, Kressel HY, Lotke PA, Spritzer CE. Magnetic resonance imaging in the evaluation of suspected osteonecrosis of the knee. Skeletal Radiol 1987;16:121-7.

10. Björkengren AG, AIRowaih A, Lindstrand A, et al. Spontaneous osteonecrosis of the knee: value of MR imaging in determining prognosis. AJR Am J Roentgenol 1990;154:331-6. 
11. Healy WL. Osteonecrosis of the knee detected only by magnetic resonance imaging. Orthopaedics 1991;14:703-4.

12. Yamamoto T, Bullough PG. Spontaneous osteonecrosis of the knee: the result of subchondral insufficiency fracture. J Bone Joint Surg [Am] 2000;82-A:858-66.

13. Lotke PA, Ecker ML. Osteonecrosis of the knee. J Bone Joint Surg [Am]1988;70-A:470-3.

14. Cruess RL. Osteonecrosis of bone: current concepts as to etiology and pathogenesis. Clin Orthop 1986;208:30-9.

15. Rális ZA, Rális HM. A simple method for demonstration of osteoid in paraffin sections. Med Lab Technol 1975;32:203-13.

16. Bullough PG. Osteonecrosis and bone infarction. In: Bullough PG, ed. Orthopaedic patho/ogy. Fourth ed. Edinburgh, etc: Mosby, 2004:347-62

17. Bullough PG. Injury and repair. In: Bullough PG, ed. Orthopaedic pathology. Fourth ed. Edinburgh, etc: Mosby, 2004:91-120.

18. Todd RC, Freeman MA, Pirie CJ. Isolated trabecular fatigue fractures in the femoral head. J Bone Joint Surg [Br] 1972;54-B:723-8.
19. Yamamoto T, Schneider R, Bullough PG. Insufficiency subchondral fracture of the femoral head. Am J Surg Pathol 2000;24:464-8.

20. Mankin HJ. Nontraumatic necrosis of bone (osteonecrosis). N Engl J Med 1992;326:1473-9.

21. Sugioka Y, Hotokebuchi T, Tsutsui H. Transtrochanteric anterior rotational osteotomy for idiopathic and steroid-induced necrosis of the femoral head: indications and long-term results. Clin Orthop 1992;277:111-20.

22. Manco LG, Schneider R, Pavlov H. Insufficiency fractures of the tibial plateau. AJR Am J Roentgeno/ 1983;140:1211-15.

23. Ahuja SC, Bullough PG. Osteonecrosis of the knee: a clinicopathological study in twenty-eight patients. J Bone Joint Surg [Am] 1978;60-A:191-7.

24. Wilson JN. Watson-Jones fractures and joint injuries. Vol. 1, Fifth ed. Edinburgh: Churchill Livingstone, 1976:11-50. 